\title{
Properties of Crumb Rubber and Latex Modified Asphalt Binders using Superpave Tests
}

\author{
Muslich Sutanto ${ }^{1,2, *}$, Nura Bala ${ }^{1}$, Kemal Al Zaro $^{3}$, and Sri Sunarjono ${ }^{3}$ \\ ${ }^{1}$ Department of Civil \& Environmental Engineering, Universiti Teknologi PETRONAS, 32610 Bandar \\ Seri Iskandar, Perak, Malaysia \\ ${ }^{2}$ Institute of Self Sustainable Building, Universiti Teknologi PETRONAS, 32610 Bandar Seri Iskandar, \\ Perak, Malaysia \\ ${ }^{3}$ Department of Civil Engineering, Universitas Muhammadiyah Surakarta, 57162 Pabelan Kartasura \\ Tromol Pos 1 Surakarta, Indonesia
}

\begin{abstract}
Polymer modified binders have been used for long time to improve the quality of asphalt pavement. This study investigates the effect of crumb rubber and latex on the properties of bitumen binders. Crumb rubber and latex were added to the control 60/70 pen grade bitumen. Four different proportions of crumb rubber and latex were considered in this study: $0 \%, 4 \%, 6 \%$ and $8 \%$ by weight of bitumen binder. The effect of crumb rubber and latex were evaluated through standard penetration and softening point tests as well as dynamic shear rheometer (DSR) test. Temperature ranges of $20^{\circ} \mathrm{C}-40^{\circ} \mathrm{C}$ were used for the DSR rheological testing. The results showed that the addition of crumb rubber and latex leads to a promising improvement on the binder properties. A reduction in penetration and an increase in softening point temperature were observed with the addition of either crumb rubber or latex, this indicates improvement in stiffness and rutting resistance. The analysis on DSR results also show that the modified binders have good rutting resistance.
\end{abstract}

\section{Introduction}

Rutting and fatigue cracking are the two main parameters dictating the life of asphalt pavement structure, hence the improvement of asphalt binders in order to sustain large stresses during pavement's service life is of significant importance. Rutting is accumulative permanent deformation in pavements layers due to the accumulation of strains over time under the repetitive traffic loadings [1,2]. Rutting in asphalt pavements lead to the reduction in both structural and service life performance of the pavement. The properties of pavement materials are critical factors in determining rutting potential of the pavement. Rutting in pavements depends to a large extent on the stiffness of the asphaltic mixture, which in turn also depends entirely on the stiffness of the binder material $[3,4]$.

\footnotetext{
*Corresponding author: muslich.sutanto@utp.edu.my
} 
The trend of significant increase in traffic volumes and axle loads coupled with poor bitumen performance on different weather conditions, results in placing much emphasis in its modification to resist defects like moisture damages, deformations and fatigue cracking [5]. Polymers such as thermoplastic elastomers and plastomers were found to be among the best materials for bitumen modification after yielding several improvements on the modified binders $[6,7]$. The major benefits recorded in applying polymers are reduction in temperature sensitivity, increasing resistance to permanent deformation, higher stiffness at high temperature, good moisture resistance, resistance to cracking at lower temperatures, and longer fatigue life $[8,9]$.

Some among the favourable polymers applied for bitumen modification are polyolefins such as polyethylenes, these includes; low-density polyethylene (LDPE), linear low density polyethylene (LLDPE), high density polyethylene (HDPE) and polypropylenes with their copolymers $[10,11]$. Polyolefins polymers when added to bitumen provide several benefits such as enhancement in properties during service life of pavement, improvement in thermomechanical resistance, increase in adhesion and elasticity of binder [12-14]. Despite the achievements recorded with polymers, several challenges still exist. The major problems related to polymer modified bitumen are lack of morphological stability during hot storage (phase separation), poor resistance to ageing (oxidation), poor compatibility with bitumen and high cost of modification among others $[8,15]$.

Nowadays, sustainability has become primary factors in construction industries. The use of waste and recycled materials captures broad interest from both academic and pavement industries. The use of renewable resources has also been encouraged in many sectors of construction. Crumb rubber and latex are among the materials gaining the interest to be widely used in road pavement construction. Therefore, this study is aimed to investigate the effect of crumb rubber and latex on the properties asphalt binder using conventional and DSR rheological tests.

\section{Materials and methods}

\subsection{Materials}

Bitumen binder grade 60/70 penetration was used for the preparation of modified binders blend in this study. Crumb rubber and latex were used for the binder modification to form modified blends. The nominal size of the crumb particles used was $0-1$ millimetre.

\subsection{Methods}

\subsubsection{Preparation of modified binders}

The modified binders were prepared using a bench-top multi mix high shear mixer by adding various percentages $(4 \%, 6 \%$ and $8 \%)$ of crumb rubber and latex by weight of bitumen binder. 60/70 pen grade binder was used for this study, additives were added to the required amount of base binder at a high shearing rate of $4000 \mathrm{rpm}$, the mixing continued for duration of 2 hours until crumb rubber and latex dissolves completely on the base binder.

\subsubsection{Penetration test}

Penetration test was conducted based on ASTM D5-13 specification to evaluate the consistency of the modified binders. According to the specification, the test is conducted at a temperature of $25^{\circ} \mathrm{C}$. The binder sample is subjected to an applied load of $100 \mathrm{~g}$ for duration 
of 5 seconds. This load application produces penetration depth in of the sample tested. The penetration depth produced is recorded as the sample penetration value.

\subsubsection{Softening point test}

Ring and ball softening point test was conducted based on ASTM D36-12 specification. Softening point test characterises and evaluates the temperature at which asphalt binder sample softens. The temperature at which bitumen binder sample cannot support a $3.5 \mathrm{~g}$ steel ball is recorded as the temperature or softening point temperature of the binder sample. During the test the binder sample is heated at a constant temperature rate of $5^{\circ} \mathrm{C} / \mathrm{min}$ throughout.

\subsubsection{Rheological analysis}

Rheological analysis was conducted using a Malvern Kinexus dynamic shear rheometer (DSR). The DSR characterise the viscoelastic rheological properties of binders especially if the binder is modified. Temperature sweep test was conducted using the DSR and the mode of loading used was controlled strain loading mode. Temperature ranges of $20-40{ }^{\circ} \mathrm{C}$ with loading frequency of $10 \mathrm{rad} / \mathrm{s}$ were used for the investigation of viscoelastic properties. The main viscoelastic parameters obtained are complex modulus $\left(\mathrm{G}^{*}\right)$ and phase angle $(\delta)$. To test each sample, a melted sample of weight about $1.0 \mathrm{~g}$ was placed on the lower plate of the DSR. The parallel upper DSR plate was lowered to a testing gap geometry of height of $1 \mathrm{~mm}$ or $2 \mathrm{~mm}$ plus $50 \mu \mathrm{m}$. Excess binder sample around the two plates was trimmed out completely. The DSR plates were then adjusted to the required testing gap of $1 \mathrm{~mm}$ or $2 \mathrm{~mm}$ depending on the DSR plate geometry.

\subsubsection{Aging method}

Rolling thin film oven test (RTFOT) test was performed on the binders in accordance to ASTM D2872 standard specification. The RTFOT test simulates binders short term aging occurrence caused by oxidation which usually happens during mixing of binders, compaction or early stage of pavement life. For RTFOT test, binder samples of 35-gram weight was poured into RTFOT glass containers. The containers containing binder samples were then placed in the RTFOT carriage with the top opening of the containers directly facing a jet of air inside and then closed. Ageing process continues for 85 minutes with the carriage rotating at speed of $15 \mathrm{rpm}$ at an uninterrupted temperature of $163^{\circ} \mathrm{C}$

\section{Results and discussion}

\subsection{Penetration test}

Figure 1 and 2 presents the penetration test result of binder containing crumb rubber (CR) and latex before and after RTFOT aging. Both before and after RTFOT aging, it can be seen that, the modified binders have lower penetration values as compared to the control binder. This indicates that both crumb rubber and latex have significant effect on reduction in penetration values of the modified binders. The significant reduction in penetration values may be beneficial in improving the modified binder resistance against temperature defects which can be expected to increase its durability and performance during service life. Less 
noticeable reduction in penetration value was observed after RTFOT aging. This indicates that the aged binder was less sensitive to both crumb rubber and latex.

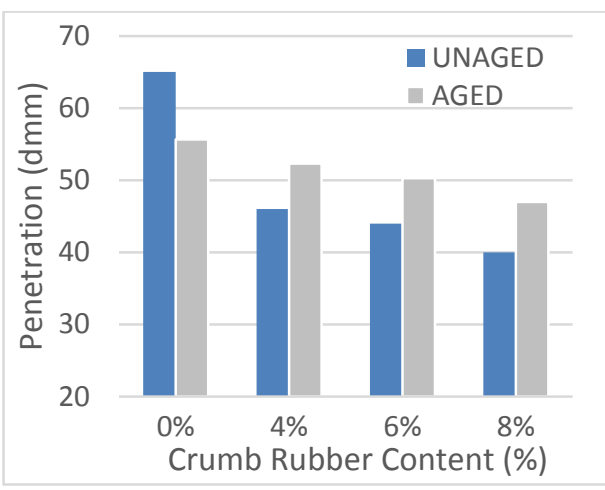

Fig.1. Penetration test of unaged and RTFOT aged crumb rubber modified binder

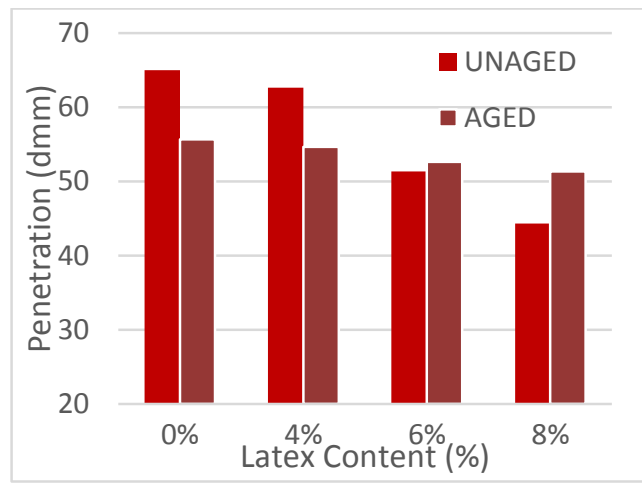

Fig. 2. Penetration test of unaged and RTFOT aged latex modified binder

\subsection{Softening point test}

Figure 3 and 4 presents the softening point temperature test results for crumb rubber and latex modified binders before and after RTFOT aging. It can be seen that the modified binders have higher softening point temperature as compared to control unmodified binder. This indicates that addition of crumb rubber and latex significantly increases the stiffness of the modified binders. The increment in softening point temperature is observed to be increase with increase in both additives content. The increase in softening point temperature for the modified binders after RTFOT shows that the binders will not easily aged during service life which leads to reduction in pavement performance under actions of temperature, and this will make the binders to be more resistant against rutting.

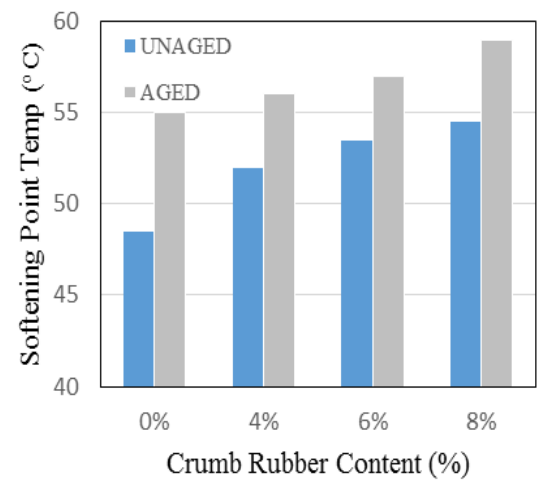

Fig. 3. Softening point temperature test of unaged and RTFOT aged crumb rubber modified binder

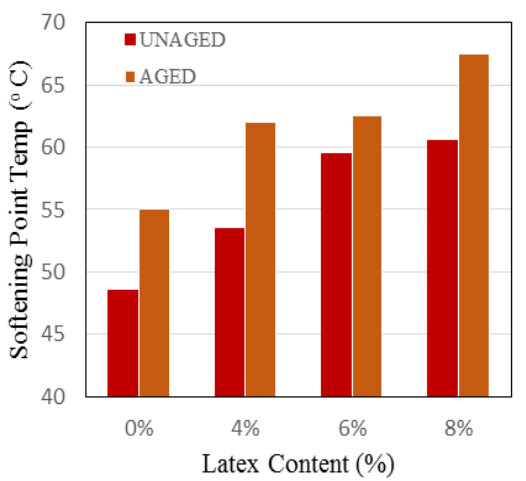

Fig. 4. Softening point temperature test of unaged and RTFOT aged latex modified binder 


\subsection{DSR rheological analysis}

\subsubsection{Isochronal plots}

Figure 5 and 6 presents the isochronal plot of complex modulus for latex and crumb rubber modified binders. It can be seen that; the modified binders show an increase in complex modulus values as compared to the control unmodified binder. The increase in complex modulus values is observed to be more significant with increase in both additives content. This shows that the additives have significant effect on improvement of the binder's viscoelasticity. The increase in complex modulus observed in the modified binders indicates that the viscoelastic properties of the control binder were improved due to addition of crumb rubber and latex, this will help in improving the stiffness of the modified binders. It can also be seen that, for the modified binders, there is slight increase in $\mathrm{G}^{*}$ at lower additive contents, but at higher temperatures, greater increment in $G^{*}$ values was observed, this indicates that, higher temperatures the binder will be more elastic which increases binder's resistance to permanent deformation. Comparing the unaged and RTFOT aged binders, it can be seen that there is significant increase in $\mathrm{G}^{*}$ values showing that aging has less effect on the modified binders.

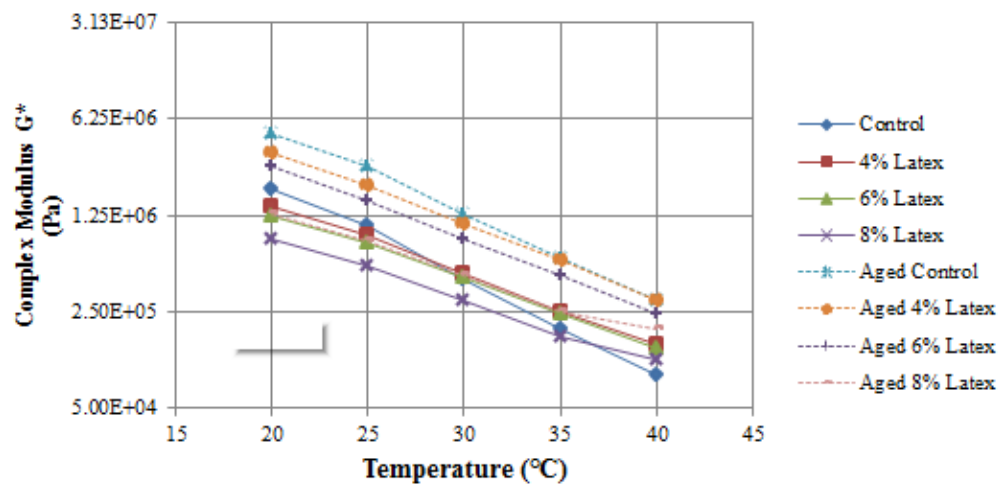

Fig. 5. Isochronal plot of complex modulus for latex modified binder

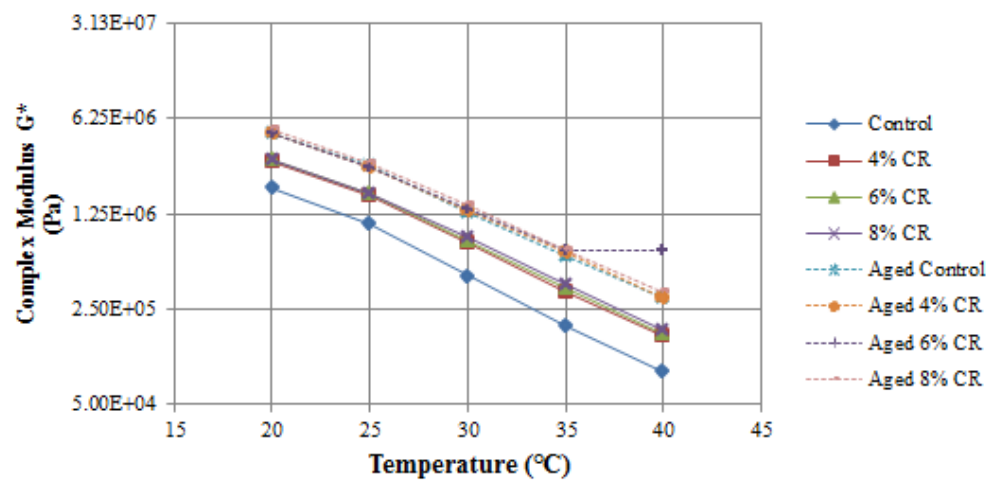

Fig. 6. Isochronal plot of complex modulus for crumb rubber modified binder

Figure 7 and 8 presents the isochronal plot of phase angle for latex and crumb rubber modified binders. It can be observed that, the modified binders have lower phase angle values 
as compared to control unmodified binder. This shows that addition of both crumb rubber and latex significantly causes a reduction in phase angle values of the modified binders which indicates improvement in elasticity of the modified binders. Also, the decrease in phase angle values as additives were added especially at intermediate temperatures confirms the formation of improved viscoelastic modified blend which will enhances the binder's performance.

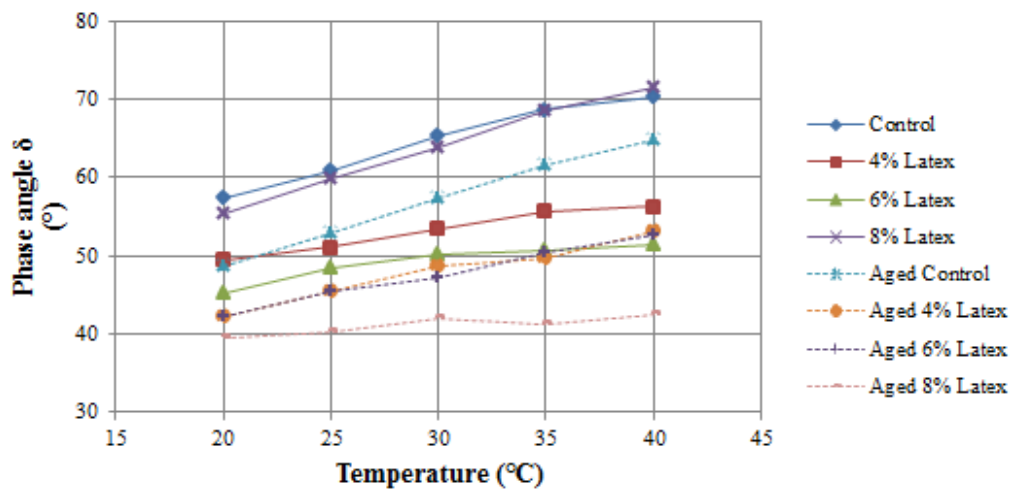

Fig. 7. Isochronal plot of phase angle for latex modified binder

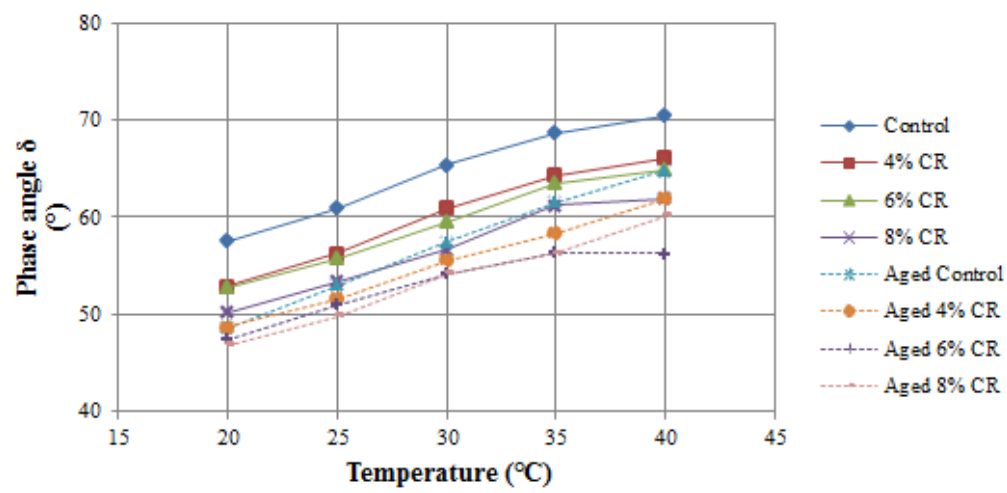

Fig. 8. Isochronal plot of phase angle for crumb rubber modified binder

\subsubsection{Rutting parameter}

To estimate the rutting resistance of the modified binders, a ratio $\left(\mathrm{G}^{*} / \sin \delta\right)$ is used as specified by Superpave specifications. Superpave provides a limit of $\mathrm{G}^{*} / \sin \delta \geq 1 \mathrm{kPa}$ for unaged binder and $\mathrm{G}^{*} / \mathrm{sin} \delta \geq 2.2 \mathrm{kPa}$ for short term aged binder [16] as the minimum required value for rutting resistance of binders. Figure 8 and 9 presents the rutting parameter $\left(\mathrm{G}^{*} / \mathrm{sin} \delta\right)$ for latex and crumb rubber modified binders at different temperatures. It can be seen that, both before and after RTFOT aging, the modified binders have higher $\mathrm{G}^{*} / \mathrm{sin} \delta$ values compared to the control binders, this indicates that the modified binders will have higher resistance to rutting deformation since higher $\mathrm{G}^{*} / \sin \delta$ values signifies better rutting resistance. Also, it can be seen that both modified binders have $\mathrm{G}^{*} / \sin \delta>1$ before aging and 
$\mathrm{G}^{*} / \sin \delta>2.2$ after RTFOT, that is all above the minimum required value, this shows that the binders will have adequate resistance against rutting deformation.

However, it can also be seen that, after RTFOT aging, the modified binders show significant increase in rutting parameter $\left(\mathrm{G}^{*} / \mathrm{sin} \delta\right)$ at all temperature ranges. The significant increase in rutting parameter indicates that aging has less effect on the modified binders. Since aging is inevitable in asphalt binders but addition of crumb rubber and latex can help to delay aging on the binders.

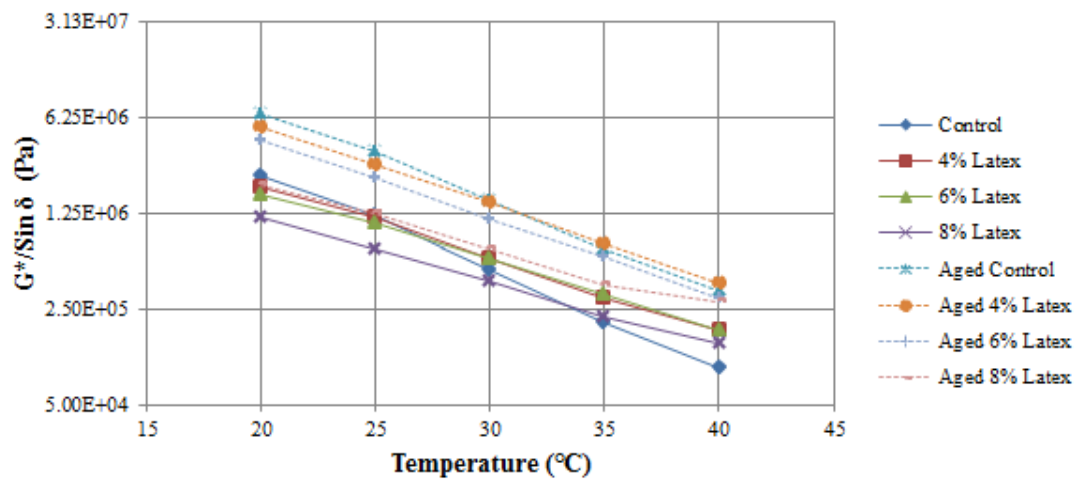

Fig. 9. Rutting parameter of latex modified binder

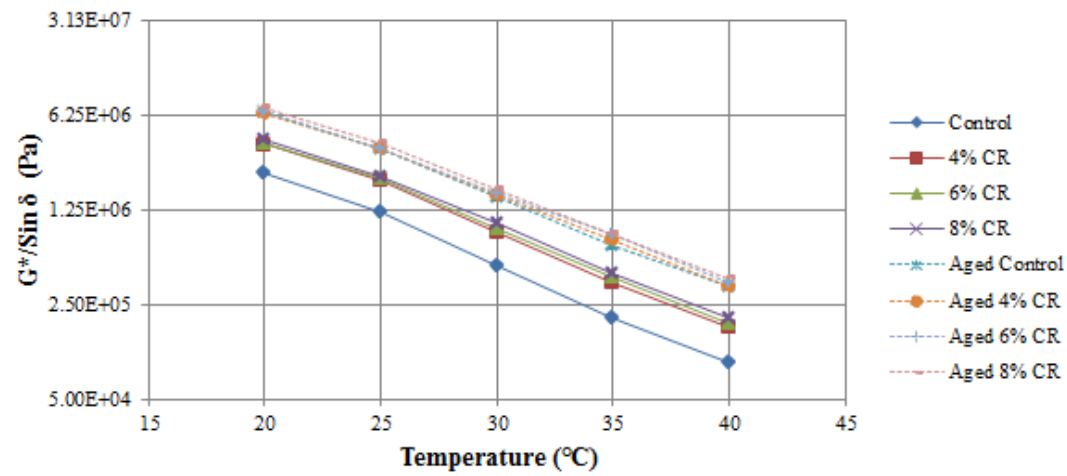

Fig. 10. Rutting parameter of crumb rubber modified binder

\section{Conclusions}

Based on the results in this study, the following conclusions can be drawn:

- Conventional test shows that there is decrease in values of penetration with increase in softening point temperature of the modified binders. This indicates improvement in binder hardness and resistance to temperature effects.

- Analysis of DSR rheological test shows that, crumb rubber and latex improves the viscoelastic rheological properties of the modified binders at temperatures tested.

- Superpave rutting estimations shows that, the modified binders are more resistant to deformation and aging has less effect on the binders, this makes them more suitable for paving applications compared to control unmodified binder. 


\section{Acknowledgement}

The authors would like to thank Universiti Teknologi PETRONAS for the financial support in this research through the Short Term Internal Research Fund (STIRF). We would also acknowledge Universitas Muhammadiyah Surakarta for the collaboration through Research Attachment Program at Universiti Teknologi PETRONAS.

\section{References}

1. A. Khodaii, and A. Mehrara, Evaluation of permanent deformation of unmodified and SBS modified asphalt mixtures using dynamic creep test. Construction and Building Materials,. 23, 7 p. 2586-2592(2009).

2. N. Bala, et al., Rheological and rutting evaluation of composite nanosilicapolyethylene modified bitumen. Proceedings of the 7th International Conference on Key Engineering Materials (ICKEM 2017) held between 11th to 13th March 2017, Penang Malaysia. IOP Conference Series: Materials Science and Engineering, 201, 1 (2017).

3. R. Imaninasab, Effect of granular polymers on rutting performance of SMA with respect to modification process. Construction and Building Materials,. 130: p. 6472 (2017).

4. N. Bala, M. Napiah, and I. Kamaruddin, Nanosilica composite asphalt mixtures performance-based design and optimisation using response surface methodology. International Journal of Pavement Engineering,: p. 1-12 (2018).

5. B. Sengoz, and G. Isikyakar, Evaluation of the properties and microstructure of SBS and EVA polymer modified bitumen. Construction and Building Materials, 22, 9 p. 1897-1905 (2008).

6. G.D. Airey, Rheological properties of styrene butadiene styrene polymer modified road bitumens 定. Fuel,. 82, 14: p. 1709-1719 (2003).

7. N. Bala, I. Kamaruddin, and M. Napiah, The Influence of Polymer on Rheological and Thermo Oxidative Aging Properties of Modified Bitumen Binders. Jurnal Teknologi,. 79, 6 p. 69-73(2017).

8. J. Zhu, B. Birgisson, and N. Kringos, Polymer modification of bitumen: Advances and challenges. European Polymer Journal, 54 p. 18-38 (2014).

9. N. Bala, I. Kamaruddin, and M. Napiah, The Influence of Polymer on Rheological and Thermo Oxidative Aging Properties of Modified Bitumen Binders. Jurnal Teknologi, 2017. 79(6): p. 69 - 73.

10. V. Punith, V. and A. Veeraragavan, Behavior of reclaimed polyethylene modified asphalt cement for paving purposes. Journal of Materials in Civil Engineering, 23, 6 p. 833-845 (2010).

11. C. Fang, et al., Combined modification of asphalt by waste PE and rubber. Polymer composites, 29, 10 p. 1183-1187(2008).

12. C. Fuentes-Audén, et al., Evaluation of thermal and mechanical properties of recycled polyethylene modified bitumen. Polymer Testing, 27, 8 p. 1005-1012 (2008).

13. A. Pérez-Lepe, F. Martínez-Boza, and C. Gallegos, Influence of polymer concentration on the microstructure and rheological properties of high-density polyethylene (HDPE)-modified bitumen. Energy \& fuels, 19, 3 p. 1148-1152 (2005). 
14. A. Fawcett, et al., Blends of bitumen with polyethylenes. Polymer, 40, 23 p. 63376349(1999).

15. C. Ouyang, et al., Improving the aging resistance of styrene-butadiene-styrene triblock copolymer modified asphalt by addition of antioxidants. Polymer degradation and stability, 91, 4: p. 795-804(2006).

16. T.W. Kennedy, et al., Superior performing asphalt pavements (Superpave): The product of the SHRP asphalt research program. Strategic Highway Research Program, National Research Council, Report No. SHRP-A-410, (1994). 